\title{
SÍFILIS EM GESTANTES DE SALVADOR: ANÁLISE DA SOROPREVALÊNCIA E POSSÍVEIS FATORES PARA TRANSMISSÃO VERTICAL
}

\author{
Alan Oliveira Duarte* \\ Fernanda Washington de Mendonça Lima ${ }^{* *}$
}

\begin{abstract}
RESUMO: A transmissão vertical da sífilis se mantém como um grande desafio para a saúde pública, demandando novas estratégias de vigilância epidemiológica. Apesar de as medidas de controle da sífilis materna e congênita estarem disponíveis no Brasil, existem dificuldades da rede em prover o diagnóstico laboratorial da infecção durante 0 pré-natal. 0 conhecimento da prevalência da doença funciona como um importante indicador da qualidade da assistência pré-natal, fornecida pelo Sistema Único de Saúde. 0 presente trabalho visa identificar a soroprevalência da sífilis em gestantes e recém-nascidos em Salvador, Bahia, por meio dos métodos sorológicos treponêmicos e não treponêmicos, e determinar possíveis fatores de risco socioeconômicos, associados à chance de se adquirir a infecção, por meio de análise estatística dos dados obtidos por um questionário. A soroprevalência encontrada foi de 4,07\% (31 pacientes de 762 participantes), significativamente superior à relatada nos últimos boletins epidemiológicos. Os dados socioeconômicos não apresentaram valores estatisticamente significativos, mas descrevem hábitos de risco da população gestante de Salvador que demandam mais educação em saúde, a fim de se controlar a propagação da infecção.
\end{abstract}

PALAVRAS-CHAVE: Imunologia; Sífilis Congênita; Soroepidemiologia.

\section{SYPHILIS IN PREGNANT WOMEN IN SALVADOR, BRAZIL: ANALYSIS OF SERUM PREVALENCE AND POSSIBLE FACTORS FOR VERTICAL TRANSMISSION}

\begin{abstract}
The vertical transmission of syphilis is still a great challenge in public health and requires new strategies in epidemiological surveillance. In spite of the control in maternal syphilis, several difficulties exist to diagnose the infection in the laboratory during the pre-natal period. Prevalence of the disease is an important indicator for the pre-natal assistance quality provided by the Brazilian Health System. Current essay identifies the serum prevalence of syphilis in pregnant women and newly-born children in Salvador, Brazil, by treponemic and não-treponemic serological methods, and determines possible socio-economical risk factors associated to possibility in being infected by statistical data analyses provided by a questionnaire. Sero-prevalence reached 4.07\% (31 patients in 762 participants), significantly higher than that reported in the latest Epidemiological Bulletins. Socio-economic data failed to provide significant statistical rates but describes risk habits of the pregnant population in Salvador, demanding more health information to control the spread of the disease.
\end{abstract}

KEYWORDS: Immunology; Congenital Syphilis; Serum Epidemiology.

\section{INTRODUÇÃO}

A sífilis é uma doença infecciosa de evolução geralmente crônica, causada pela bactéria Treponema pallidum. A transmissão pode ocorrer por meio do contato sexual (desenvolvendo a forma adquirida da infecção), por transfusão sanguínea e por transmissão vertical (infecção congênita), tendo destaque, nesse segundo caso, por ser a segunda doença com maiores taxas de transmissão durante 0 ciclo grávidopuerperal (BRASIL, 2006). É interessante ressaltar que, embora seja uma doença que ainda hoje gere impacto às instituições de saúde pública do país, pode ser controlada por meio de medidas preventivas, pois

\footnotetext{
*Graduado em Farmácia pela Universidade Federal da Bahia (UFBA), Faculdade de Farmácia; E-mail: alanduarte.ufba@gmail.com

** Doutora em Biologia Celular e Molecular pela Fundação 0swaldo Cruz, Brasil; Docente Adjunta da Universidade Federal da Bahia (UFBA), Salvador, Brasil
} 
pode ser detectada por meio de métodos de diagnóstico laboratorial sensíveis e baratos e é facilmente tratada com medicamentos de custo baixo, disponíveis pelo SUS (BRASIL, 2007).

A sífilis apresenta um espectro diversificado de manifestações clínicas, sendo classificada, de acordo com 0 grau das lesões, em sífilis primária, secundária e terciária (BRASIL, 2007), podendo ainda haver a infecção assintomática. Na gestante, a infecção pode ser transmitida por via transplacentária, em qualquer fase da gestação e em qualquer estágio da doença, ou por transmissão direta no canal do parto (SÃO PAULO, 2008). A sífilis congênita é classificada em precoce, quando diagnosticada em até dois anos de vida da criança, e tardia, quando diagnosticada após esse período (BRASIL, 2006).

Desde 1986, a sífilis congênita é de notificação compulsória, tendo sido incluída no Sistema de Informação de Agravos de Notificação, enquanto a sífilis em gestantes foi incluída em 2005. Segundo relatório do Boletim Epidemiológico - Sífilis de 2012, do Ministério da Saúde, entre 2005 e junho de 2012, foram notificados no Sinan 57.700 casos de sífilis em gestantes, dos quais, a maioria ocorreu nas regiões Sudeste e Nordeste, com 21.941 (38,0\%) e 14.828 (25,7\%) casos, respectivamente (BRASIL, 2012). Esse valor elevado, segundo relato do próprio boletim, é por "um aumento dos esforços de fortalecimento dos serviços de pré-natal, com a realização de diagnóstico precoce e tratamento".

Na região Nordeste, ainda segundo o boletim epidemiológico, a incidência da sífilis congênita parece diminuir, demonstrando uma melhora na qualidade do atendimento pré-natal e do diagnóstico precoce, 0 que se reflete em um número progressivamente maior de casos diagnosticados, permitindo 0 tratamento e cura de grande parte das pessoas infectadas. Em Sergipe (INAGAKI et al., 2009) foi encontrada uma soroprevalência de $0,9 \%$ entre as 9.550 gestantes sergipanas testadas, sendo a mais prevalente dentre as infecções investigadas no mesmo estudo (CMV, toxoplasmose, HIV, rubéola, sífilis).

Os dados sobre a situação epidemiológica da sífilis em gestantes e da sífilis congênita no município de Salvador-Bahia ainda são escassos. A literatura disponível geralmente envolve estudos de vigilância, analisando as fichas de investigação/notificação, como 0 realizado por Almeida e Pereira (ALMEIDA; PEREIRA, 2007) os quais têm como limitação a subnotificação dos casos pelos sistemas de vigilância, 0 que compromete a interpretação e representatividade dos dados. Em trabalho recente realizado por Nóbrega (NÓBREGA et al., 2013), foi realizada pesquisa sobre a soroprevalência da sífilis e da infecção pelo HIV em parturientes de uma maternidade em Salvador. Os resultados mostraram uma prevalência baixa de ambas as infecções, mas sugere um alto risco de reinfecção das gestantes mesmo após o diagnóstico, pela ausência de cuidados de saúde por parte dos cônjuges, aliada à prática do sexo sem proteção entre os casais, principalmente por questões sociais que envolvem as relações de confiança entre marido e esposa.

0 conhecimento da prevalência das infecções congênitas é fundamental para a formulação de políticas de saúde materno-infantil. Segundo Lorenzi e Madi (LORENZI; MADI, 2001), o Ministério da Saúde incluiu a sífilis congênita como um indicador da qualidade e abrangência da atenção básica de cada município, "uma vez que esta reflete diretamente a qualidade da assistência perinatal, em particular da atenção pré-natal disponível a cada população".

Como afirma Nóbrega (NÓBREGA et al., 2013), nos últimos anos tem-se modificado a prevalência das Doenças Sexualmente Transmissíveis na população de países em desenvolvimento, tendo em vista as mudanças tanto nos aspectos da saúde e prevenção como nos aspectos sociais, aumento do número de pessoas na classe média, redução do número de filhos. Essas recentes mudanças no perfil epidemiológico das DST sustentam a necessidade de dados sempre atualizados sobre a soroprevalência da sífilis em nosso meio, pois são necessárias informações que permitam avaliar se as medidas públicas, adotadas principalmente em nível de medidas preventivas no combate à sífilis em gestantes e à sífilis congênita, têm trazido resultados esperados na diminuição da prevalência da infecção. 


\section{METODOLOGIA}

Esta pesquisa foi parte de um projeto maior, intitulado "Agentes de Infecção Congênita em gestantes de Salvador-BA: Investigação da prevalência e análise de fatores de risco", desenvolvido no Serviço de Imunologia de Doenças Infecciosas (SIDI) da Faculdade de Farmácia da Universidade Federal da Bahia. Por meio desse projeto, realizaram-se diversos trabalhos de iniciação científica (graduação), mestrado e doutorado (pós-graduação) que investigaram possíveis causas de infecções congênitas entre as gestantes de Salvador-BA.

0 projeto "Agentes de Infecção Congênita em gestantes de Salvador-BA: Investigação da prevalência e análise de fatores de risco", que inclui em seu escopo o presente trabalho, foi avaliado e aprovado pelo Comitê de Ética em Pesquisa da Escola de Enfermagem da UFBA, cujo $\mathrm{n}^{0}$ do parecer é 384.209. As gestantes foram apresentadas ao "Termo de Consentimento Livre e Esclarecido" e foram orientadas sobre o caráter voluntário da pesquisa, que não envolvia nenhuma forma de custo adicional ou remuneração, sobre o procedimento para a coleta e armazenamento do material biológico, o período de armazenamento e sigilo total acerca de suas informações pessoais e resultados laboratoriais, podendo deixar de participar da pesquisa caso desejasse, a qualquer momento.

0 estudo foi realizado em três etapas principais: coleta de material biológico, determinações laboratoriais e análises estatísticas. Participaram do estudo as gestantes e seus neonatos atendidos na Maternidade Climério de Oliveira (MCO), Salvador Bahia, entre o período de janeiro a dezembro de 2014.A amostra populacional foi selecionada por conveniência, sendo composta por 762 gestantes (número amostral suficiente para se obter poder estatístico mínimo de $95 \%$ ). As gestantes foram abordadas durante seu atendimento na MCO, sem distinção do momento da gravidez em que se encontravam, e foram convidadas a participar da pesquisa segundo os termos do Termo de Consentimento Livre e Esclarecido apresentado a elas. Foram então coletados os dados socioeconômicos e epidemiológicos por meio de um questionário padronizado, que continha informações de interesse para esta pesquisa, as quais foram analisadas estatisticamente.

Na sequência, foram coletadas amostras de sangue das gestantes e dos recém-nascidos pela equipe do Laboratório de Análises Clínicas da MCO, que também foi responsável pelo acondicionamento e transporte das mesmas ao Serviço de Imunologia de Doenças Infecciosas (SIDI) da Faculdade de Farmácia da UFBA, onde foram realizadas as análises laboratoriais. Foram obtidos $4 \mathrm{~mL}$ de sangue da paciente e $1 \mathrm{~mL}$ de sangue de seu RN, colhidos com o uso do sistema a vácuo em tubo seco. As amostras foram coletadas na MCO, devidamente identificadas no momento da coleta, acondicionadas e enviadas. A identificação das amostras continha o nome da mãe e data da coleta. Para amostra de recém-nascido, antes do nome da mãe era escrita a expressão "RN de", e, para 0 caso de nascimento de gêmeos, foram diferenciados como "RN 1 de", "RN 2 de", e assim sucessivamente. Após as análises laboratoriais, os resultados dos exames realizados foram encaminhados para a equipe médica da MCO, para que, se necessário, fossem realizados os procedimentos clínicos cabíveis.

\subsection{MÉTODO TREPONÊMICO}

Para a pesquisa de IgG específica para Treponema pallidum foi utilizado kit de ELISA indireto de última geração com peptídeos sintéticos e/ou recombinantes do Treponema pallidum. 0s ensaios foram realizados, seguindo o protocolo do kit, por meio de aparelho de automação ou semiautomação.

\subsection{MÉTODO NÃO TREPONÊMICO}

Para a determinação e quantificação de anticorpos anticardiolipina, foi utilizado 0 método de floculação, conhecido por VDRL (Veneral Disease Research Laboratory).

0 método escolhido como método treponêmico (ELISA) foi de triagem da população 
e 0 método não treponêmico (VDRL), como método semiquantitativo para ambos, mãe e RN. Decidiuse que seria realizado nessa ordem pelas seguintes vantagens do método treponêmico:

1. a elevada sensibilidade e especificidade dos métodos treponêmicos imunoenzimáticos. Embora 0 teste de VDRL seja rápido, barato e possa ser empregado até como critério de cura por apresentar títulos que se correlacionam com a clínica, ele não apresenta especificidade, podendo ter resultados falso positivos para diversas condições clínicas ou mesmo fisiológicas, como a própria gravidez;

2. a possibilidade do uso da automação para testar numerosas amostras da pesquisa de forma mais rápida e proficiente, reduzindo os erros decorrentes da realização manual dos testes.

\subsection{ANÁLISE ESTATÍSTICA}

Os dados encontrados no decorrer do estudo foram tabulados para obtenção de medidas de centralidade e dispersão. Os programas estatísticos SPSS $®$ 9.0 (ou SPSSR 17.0 for Windows $®$ ) e GraphPad InStat ${ }^{\circ}$ foram utilizados para as análises estatísticas. 0 teste do ${ }^{2}$ serviu para comparações entre proporções com correção de Yates, aceitando-se diferenças com significância estatística quando $p \leq 0,05$. 0 s dados clínicos e laboratoriais foram confrontados para se verificar uma possível correlação entre eles.

\section{RESULTADO}

Foram realizados testes de ELISA para pesquisa de IgG específica para $\mathrm{T}$. pallidum de 762 gestantes, dentre as quais, 47 (6,2\% do total) apresentaram resultado positivo. Entretanto, sabe-se que os testes treponêmicos, dentre os quais o ELISA, podem se apresentar positivos em pacientes que se trataram e curaram a infecção, processo conhecido como "cicatriz sorológica" (CAMPOS, 2014). Para se diferenciar entre doença ativa ou cicatriz sorológica, realizou-se o teste do VDRL, obtendo-se um resultado de 31 gestantes com títulos positivos no teste (prevalência de 4\%). Infelizmente, pelas limitações no volume de amostra obtido para 0 projeto, das 47 gestantes positivas por ELISA, 11 não tiveram o teste de VDRL realizado por falta de amostra, portanto, nem estas pacientes nem seus RNs foram considerados no cálculo da prevalência.

Os resultados do VDRL dos filhos de mães que tiveram o teste de VDRL positivo apresentaram resultados relevantes. Nota-se que a maioria destes (48\%) apresentou resultados positivos, o que indica fortemente a chance de a infecção ter passado da mãe para o filho; entretanto essa é uma conclusão que necessita ser analisada com cautela, considerandose que os anticorpos reagínicos, detectados no teste, são da classe IgG e passam pela placenta da mãe para 0 filho. 0 diagnóstico de sífilis congênita requer um acompanhamento mais detalhado, tanto clínico quanto laboratorial, e um estudo de acompanhamento dos desfechos seria necessário para se alcançar conclusões mais seguras.

Tabela 1. Resultados do teste de VDRL de recém-nascidos (RNs) de mães que apresentaram VDRL positivo

\begin{tabular}{l|c|c}
\hline \multicolumn{2}{l}{ Resultado dos testes de VDRL de RNs filhos de mães com VDRL positivo } \\
\hline VDRL do RN & Número de RNs & Percentagem do total \\
\hline Negativo & 11 & $36 \%$ \\
Positivo & 15 & $48 \%$ \\
Não realizados & 5 & $16 \%$ \\
\hline
\end{tabular}


No questionário socioeconômico, as gestantes foram perguntadas quanto a diversos parâmetros, dentre os quais se destacam para a análise estatística da sífilis em gestantes: se a paciente já teve algum aborto, se teve alguma doença detectada durante a gravidez, se tinha parceiro sexual fixo, se utilizava preservativo na relação sexual, além de idade e grau de escolaridade.
Quanto ao questionamento se a paciente já teve algum aborto, observou-se que um número considerável das gestantes da pesquisa relatou já ter tido um aborto antes da gravidez atual (220 gestantes, $29 \%$ do total), mas dentre as gestantes positivas para sífilis, a maioria afirmou não ter sofrido um aborto antes (29 gestantes, $62 \%$ das positivas por ELISA, $\mathrm{P}=0,020)$.

Tabela 2. Número de abortos prévios à gravidez atual em gestantes positivas para sífilis pelo método de ELISA

\begin{tabular}{c|c|c}
\hline \multicolumn{3}{c}{ Número de abortos em gestantes soropositivas para sífilis } \\
\hline Número de abortos & Número de gestantes & Percentagem do total \\
\hline Nenhum & 29 & $62 \%$ \\
Um & 16 & $34 \%$ \\
Dois & 1 & $2 \%$ \\
Três ou mais & 1 & $2 \%$ \\
\hline
\end{tabular}

As gestantes foram perguntadas se já haviam tido alguma doença antes ou durante a gravidez, a fim de se saber quantas tinham ciência de ter sido detectada a sífilis durante 0 pré-natal. Das 762 gestantes, 13 $(1,7 \%)$ afirmaram ter recebido o diagnóstico de sífilis, 161(21\%) tiveram infecção urinária, 141(18,5\%) declararam outras doenças (diabetes gestacional, anemia, aumento da pressão etc.).

Considerando-se que a sífilis constitui uma das principais DSTs, os parâmetros "ter parceiro sexual fixo" e "usar preservativo" constituem fatores importantes no entendimento da prevalência da infecção. A grande maioria das pacientes participantes da pesquisa possui relação conjugal estável (623 gestantes, $82 \%$ do total) e tem parceiro sexual fixo (701 gestantes, 92\% do total), e nenhuma correlação com a positividade para sífilis foi observada, pois as gestantes positivas apresentaram a mesma proporção. Quanto ao uso de preservativo pelo parceiro nas relações sexuais, 523 gestantes (69\% do total) afirmam não utilizarem, 175 (23\% do total) afirmam usar raramente, e 64 gestantes ( $8 \%$ do total) afirmam usar com frequência. Dentre as gestantes positivas para sífilis, não se observou nenhuma tendência, tendo 42,5\% (20 gestantes) afirmado que utilizam preservativo, e $57,5 \%$ (27 gestantes, $\mathrm{P}=0,088$ ), que não utilizam.

Quanto aos aspectos de faixa etária e grau de escolaridade, não se destacou nenhuma correlação com a positividade para a infecção, pois as gestantes soropositivas apresentaram distribuição com a mesma proporcionalidade que as gestantes negativas. Observou-se um maior número de pacientes positivas dentre as que tinham idade entre 15 e 35 anos (43 mães, $93 \%, P=0,460$ ) e as que afirmaram ter $2^{\circ}$ grau (26 gestantes, 56\%), proporcionais à maior parcela das participantes da pesquisa. 


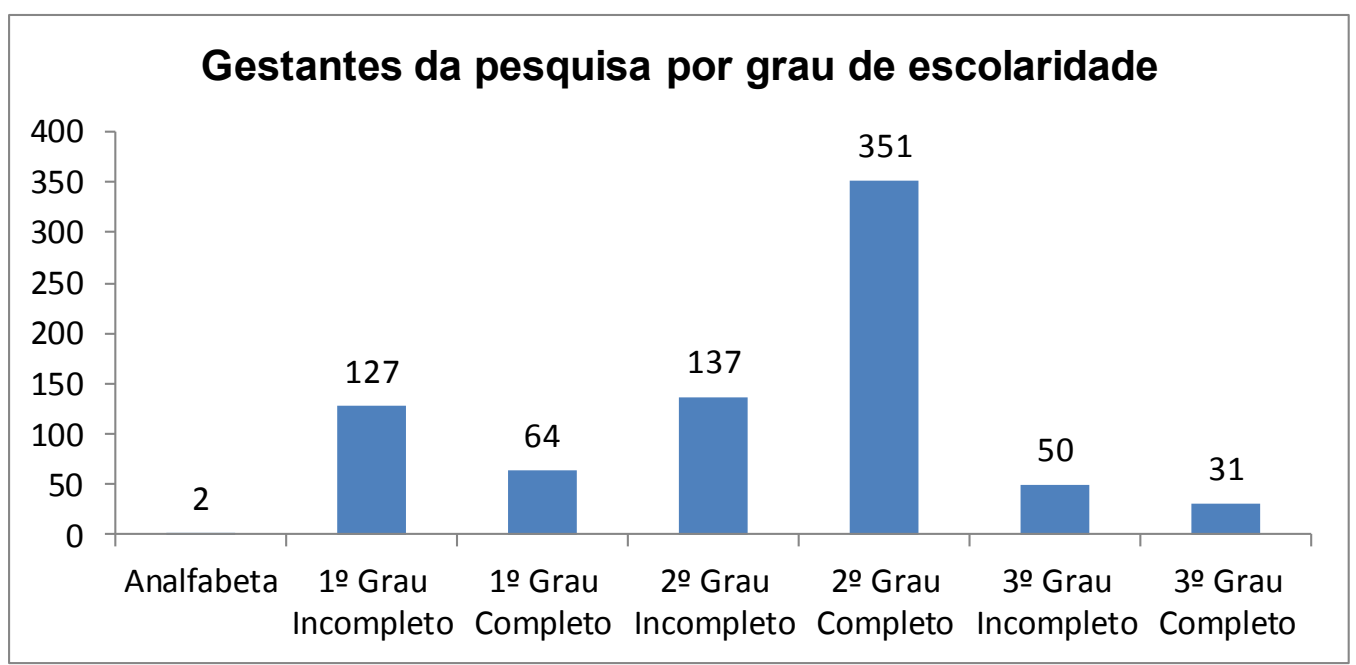

Gráfico 1. Grau de escolaridade declarada pelas gestantes participantes da pesquisa

\section{DISCUSSÃO}

A soroprevalência de sífilis em gestantes, calculada após realização de testes treponêmicos e não treponêmicos, foi de 4,07\% (31 pacientes de 762 com ELISA e VDRL positivos). Esse valor foi significativamente superior ao que foi obtido com estudos realizados na mesma região em anos anteriores, em que a prevalência encontrada não alcançou 0 valor de 1\% (NÓBREGA, 2014). Isso corrobora a hipótese de que há uma subestimação (e, adicionalmente, uma subnotificação) do número de casos de sífilis em gestantes na população soteropolitana, levantada pelos estudos de vigilância epidemiológica, realizada até o momento.

Além disso, ao se confrontar os dados obtidos pelo questionário com os dados laboratoriais, percebe-se que muitas gestantes tiveram acesso deficiente aos serviços de pré-natal, considerandose que 47 gestantes apresentaram teste sorológico positivo para sífilis, mas apenas 13 das gestantes da pesquisa tinham ciência desse diagnóstico por meio de resultados laboratoriais prévios, obtidos no pré-natal. Isso indica que as gestantes ainda estão tendo dificuldades no acesso aos serviços de saúde, decorrentes não apenas das dificuldades inerentes aos serviços de saúde pública do Brasil, mas também de condições socioeconômicas da gestante relacionadas a dificuldades de transporte, moradia, alimentação, conflitos domésticos, dentre outras problemáticas a serem enfrentadas no seu cotidiano.

Embora os resultados do questionário socioeconômico, quando analisados estatisticamente, não apresentassem índices de correlação que apontassem fatores de risco de adquirir a infecção, esses dados permitem a visualização da situação de risco das mulheres gestantes em Salvador, que descrevem uma baixa adesão ao uso de preservativo entre parceiros fixos e um número elevado de casos de aborto, com quase $30 \%$ do total das gestantes afirmando ter sofrido pelo menos um aborto antes da gravidez atual. Esses dados devem ser utilizados para se orientar a necessidade de mais ações dos órgãos governamentais, voltadas para a saúde da gestante, e para se alertar a população da importância do acompanhamento pré-natal completo e da prevenção contra doenças sexualmente transmissíveis durante a gravidez. 


\section{CONCLUSÃo}

Por meio dos resultados aqui apresentados pode-se comprovar que são necessárias medidas de ampliação do acesso do pré-natal às gestantes sob risco social, bem como um esforço em direção a ações preventivas e de conscientização da população, da importância do uso do preservativo, mesmo após a gravidez, como medida de proteção contra as diversas doenças sexualmente transmissíveis. Caso não sejam tomadas as providências cabíveis de prevenção e ampliação do acesso aos serviços de saúde, a sífilis em gestantes e a congênita, que já se apresentam como problemas emergentes de saúde pública, continuarão a provocar um número considerável de vítimas em nosso meio, tanto de gestantes como de recém-nascidos.

\section{AGRADECIMENTOS}

A equipe de pesquisadores agradece 0 apoio do Conselho Nacional de Desenvolvimento Científico e Tecnológico (CNPq) e da Fundação de Amparo à Pesquisa do Estado da Bahia (Fapesb), órgãos de fomento à pesquisa e à iniciação científica, e à equipe de médicos(as), enfermeiros(as) e bioquímicos(as) da Maternidade Climério de Oliveira da UFBA e do Serviço de Imunologia de Doenças Infecciosas (Sidi) da Faculdade de Farmácia da UFBA, que proporcionaram a realização deste trabalho.

\section{REFERÊNCIAS}

ALMEIDA, M. F. G.; PEREIRA, S. M. Caracterização epidemiológica da sífilis congênita no Município de Salvador, Bahia. Dst Jornal Brasileiro de Doenças Sexualmente Transmissiveis, Rio de Janeiro, v. 3-4, n. 1, p.144-156, 2007. Disponível em: <http://www.aids.gov.br/sites/default/files/anexos/ page/2010/44612/22_sifilis_congenita_salvador_ pdf_23137.pdf>. Acesso em: 30 jun. 2014.
BRASIL. D. S. B. Ministério da Saúde. Secretaria de Vigilância em Saúde. Programa Nacional de Dst e Aids. Protocolo para a prevenção de transmissão vertical de HIV e sífilis: manual de bolso. Brasília: Ministério da Saúde, 2007. 180p. Disponível em: <http://bvsms.saude.gov.br/bvs/publicacoes/ protocolo_prevencao_transmissao_verticalhivsifilis_ manualbolso.pdf>. Acesso em: 30 jun. 2014.

BOLETIM Epidemiológico: Sífilis, v. 1, n. 1, 2012. 15p. Disponível em: <http://www.aids.gov.br/sites/ default/files/anexos/publicacao/2012/52537/boletim_ sifilis_2012_pdf_26676.pdf >. Acesso em: 30 jun. 2014.

BRASIL. Ministério da Saúde. Secretaria de Vigilância em Saúde. Programa Nacional de Dst/aids. Diretrizes para controle da sífilis congênita: manual de bolso. Brasília: Ministério da Saúde, 2006. 70p. Disponível em: <http://bvsms.saude.gov.br/bvs/publicacoes/ manual_sifilis_bolso.pdf $>$. Acesso em: 30 jun. 2014.

CAMPOS, J. E. B. et al. Significado laboratorial dos baixos títulos de VDRL para o diagnóstico da sífilis em gestantes, à luz das provas treponêmicas. Dst Jornal Brasileiro de Doenças Sexualmente Transmissiveis, Rio de Janerio, v. 20, n. 1, p. 12-17, 2008. Disponível em: <http://www.aids.gov.br/sites/default/files/2 baixos_titulos_vdrl.pdf>. Acesso em: 15 nov. 2014.

COSTA, C. C. et al. Sífilis congênita no Ceará: análise epidemiológica de uma década. Revista da Escola de Enfermagem da Usp, São Paulo, v. 1, n. 47, p.152159, fev. 2013. Anual. Disponivel em: <http://www. scielo.br/pdf/reeusp/v47n1/a19v47n1>. Acesso em: 30 jun. 2014.

INAGAKI, A. D. M. et al. Soroprevalência de anticorpos para toxoplasmose, rubéola, citomegalovírus, sífilis e HIV em gestantes sergipanas. Revista da Sociedade Brasileira de Medicina Tropical, Brasília, v. 42, n. 5 , p.152-159, out. 2009. Disponível em: <http://www. scielo.br/pdf/rsbmt/v42n5/10.pdf $>$. Acesso em: 30 jun. 2014. 
LIMA, M. G. et al. Incidência e fatores de risco para sífilis congênita em Belo Horizonte, Minas Gerais, 20012008. Ciência \& Saúde Coletiva, Rio de Janeiro, v. 18, n. 2, p.499-506, fev. 2013. Disponível em: <http:// www.scielo.br/pdf/csc/v18n2/21.pdf>. Acesso em: 30 jun. 2014.

LORENZI, D. R. S.; MADI, J. M. Sífilis Congênita como Indicador de Assistência Pré-natal. Revista Brasileira de Ginecologia \& Obstetrícia, Rio de Janeiro, v. 23, n. 10, p.647-652, fev. 2001. Disponível em: <http:// www.scielo.br/pdf/rbgo/v23n10/8489.pdf>. Acesso em: 30 jun. 2014.

NÓBREGA, I. et al. Syphilis and HIV-1 among parturient women in Salvador, Brazil: low prevalence of syphilis and high rate of loss to follow-up in HIV-infected women. Brazilian Journal of Infectious Diseases, Salvador, v. 17, n. 2, p.184-193, mar. 2014. Disponível em: <http://www.scielo.br/pdf/bjid/v17n2/v17n2a12. pdf >. Acesso em: 30 jun. 2014.

SECRETARIA DE ESTADO DA SAÚDE. Serviço de Vigilância Epidemiológica. Coordenação do Programa Estadual DST/Aids. Sífilis congênita e sífilis na gestação. Revista Saúde Pública, v. 42, n. 4, p. 768772, 2008. Disponível em: <http://www.scielo.br/pdf/ rsp/v42n4/itss.pdf>. Acesso em: 24 Jun. 2014.

Recebido em: 27 de fevereiro de 2016 Aceito em: 20 de abril de 2016 